\title{
Penaksiran Parameter dan Pengujian Hipotesis Model Regresi Weibull Univariat
}

\section{Parameter Estimation and Hypothesis Testing on Univariate Weibull Regression Model}

\author{
Suyitno \\ Program Studi Statistika, Jurusan Matematika FMIPA Universitas Mulawarman \\ E-mail: suyitno@fmipa.unmul.ac.id
}

\begin{abstract}
In this study, a univariate Weibull regression model is discussed. The Weibull regression is a regression model developed from the Weibull distribution, that is the Weibull distribution depending on the covariates or the regression parameters. The univariate Weibull regression (UWR) model can involve the survival function model and the mean model of the response variable with the scale parameter stated in the terms of the regression parameters. The aim of this study is to estimate the UWR model parameters using the maximum likelihood estimation (MLE) method, and to test the regression parameters. The result shows that the closed form of the maximum likelihood estimator can not be found analytically, and it can be approximed by using the Newton-Raphson iterative method. The regression parameters testing involves simultaneous and partial test. The test statistic for simultaneous test is Wilk's likelihood ratio. Wilk statistic follows Chi-square distribution, which can be derived from the likelihood ratio test (LRT) method. The test statistic for partial test is Wald and it follows standard normal distribution. The alternative test statistik for partial test is squared of Wald statistic, where it follows Chi-square distribution with one degree of freedom.
\end{abstract}

Keywords : UWR, MLE, Wilk statistic, Wald statistic

\section{Pendahuluan}

Distribusi Weibull umumnya digunakan pada analisis reliabilitas, data waktu atau data lingkungan. Distribusi Weibull univariat memuat tiga parameter yaitu parameter lokasi, parameter bentuk dan parameter skala. Salah satu bentuk khusus dari distribusi Weibull univariat adalah distribusi Weibull versi skala-bentuk (scale-shape version), yakni distribusi Weibull univariat yang memuat dua parameter yaitu parameter skala dan bentuk.

Sebagai pengembangan, distribusi Weibull dapat bergantung pada kovariat atau peubah bebas (Lawless, 2003; Rinne, 2009). Distribusi Weibull dengan parameter skala tertentu (fixed) adalah termasuk distribusi keluarga eksponensial. Dalam konteks generalized liner model (GLM), model regresi Weibull tidak mempunyai fungsi penghubung kanonik (canonical link function), sehingga parameter skala atau parameter bentuk dapat dinyatakan dalam fungsi dari kovariat.

Pembahasan distribusi Weibull mudah didapat di berbagai literatur, tetapi hanya sedikit literatur yang membahas regresi Weibull. Beberapa penelitian tentang regresi Weibull antara lain adalah model regresi Weibul untuk survival time yang dikemukan oleh O,Quigley dkk, (1980). Hanagal, (2004, 2005) membahas regresi Weibull bivariat pada data sampel waktu tersensor (censored survival time). Model regresi Weibull yang dikemukakan oleh Hanagal, (2004, 2005) dikembangkan dari distribusi eksponensial yang dikemukakan oleh Freund dan Marshal-Olkin.

Penenlitian tentang teori dan aplikasi regresi Weibull masih terbatas, sementara itu banyak permasalahan di berbagai bidang (misalnya bidang kesehatan dan lingkungan) yang dapat diselesaikan menggunakan model regresi Weibull. Pembahasan regresi Weibull saat ini masih terbatas pada penaksiran parameter, dan masih sedikit yang membahas pengujian hipotesis parameter regresi.

Sebagai pengembangan model regresi Weibull, pada penenlitian ini dibahas model regresi Weibull, yaitu model mean dari peubah respon dan model fungsi survival. Pembahasan difokuskan pada teori penaksiran parameter dan pengujian hipotesis parameter regresi. Metode penaksiran parameter adalah maximum likelihood estimation (MLE). Pengujian hipotesis parameter regresi terdiri dari pengujian secara serentak dan parsial. Statistik uji pengujian parameter regresi secara serentak adalah statistik Wilk dan statistik uji pengujian parsial adalah statistik Wald. Statistik uji Wilk diturunkan berdasarkan metode likelihood ratio test (LRT) dan statistik Wald dapat diturunkan berdasarkan sifat asimtotik penaksir maximum likelihood.

Sebagai penutup bagian ini, berikut adalah struktur penulisan penelitian. Pendahuluan disajikan pada bagian pertama, pengenalan model umum regresi Weibull dibahas pada bagian kedua, penaksiran parameter disajikan pada bagian ketiga, pengujian hipotesis parameter regresi dikemukakan pada bagian keempat, tahapan analisis data dibahas pada bagian kelima dan kesimpulan penelitian disajikan pada bagian keenem.

\section{Model Regresi Weibull Univariat (RWU)}

Fungsi kepadatan peluang (FKP) peubah acak kontinu nonnegatif $Y$ berdistribusi Weibull dengan tiga parameter adalah 


$$
f(y)=\frac{\gamma}{\lambda}\left(\frac{y-\delta}{\lambda}\right)^{\gamma-1} \exp \left[-\left(\frac{y-\delta}{\lambda}\right)^{\gamma}\right],
$$

dengan $y>\delta, 0<\lambda, \gamma, \delta<\infty$, dimana $\gamma, \lambda$ dan $\delta$ berturut-turut adalah parameter bentuk (shape), parameter skala (scale) dan parameter lokasi atau location (Rinne, 2009). Bentuk khusus distribusi Weibull dengan tiga parameter adalah distribusi Weibull versi skala-bentuk, dengan FKP dinyatakan dalam persamaan berikut

$$
f(y)=\frac{\gamma}{\lambda}\left(\frac{y}{\lambda}\right)^{\gamma-1} \exp \left[-\left(\frac{y}{\lambda}\right)^{\gamma}\right] \text {. }
$$

Fungsi survival distribusi Weibull versi skala bentuk diberikan oleh

$$
S(y)=P(Y>y)=\exp \left[-\left(\frac{y}{\lambda}\right)^{\gamma}\right],
$$

dan fungsi distribusi kumulatif didefinisikan oleh $F(Y)=P(Y \leq y)=1-S(y)$

$$
=1-\exp \left[-\left(\frac{y}{\lambda}\right)^{\gamma}\right]
$$

FKP yang diberikan oleh persamaan (2) dapat diperoleh dari fungsi survival (3) dan fungsi distribusi kumulatif melalui hubungan

$f(y)=\frac{d F(y)}{d y}=-\frac{d S(y)}{d y}$.

Momem ke- $r$ distribusi Weibull versi skala-bentuk dengan FKP yang diberikan oleh persamaan (2) dapat dinyatakan dalam bentuk umum

$$
E\left(Y^{r}\right)=\lambda^{r} \Gamma_{r}\left(\frac{r}{\gamma}+1\right),
$$

dengan $\Gamma($.$) adalah fungsi Gamma dan \Gamma_{r}$ didefinisikan oleh

$$
\Gamma_{r}=\Gamma\left(\frac{r}{\gamma}+1\right) .
$$

Mean dan variansi dari peubah acak $Y$ dapat diperoleh berdasarkan persamaan (4), yaitu berturut-turut adalah

$$
\mu_{Y}=E(Y)=\lambda \Gamma\left(\frac{1}{\gamma}+1\right),
$$

dan

$$
\begin{aligned}
\operatorname{var}(Y) & =E\left(Y^{2}\right)-[E(Y)]^{2} \\
& =\lambda^{2}\left[\Gamma\left(\frac{2}{\gamma}+1\right)-\left[\Gamma\left(\frac{1}{\gamma}+1\right)\right]^{2}\right], \\
& =\lambda^{2}\left(\Gamma_{2}-\Gamma_{1}^{2}\right)
\end{aligned}
$$

serta $E\left(Y^{\gamma}\right)=\lambda^{\gamma}$.

Distribusi Weibull versi skala-bentuk dengan parameter skala tertentu (fixed) dengan suatu transformasi $T=y^{\gamma}$ adalah keluarga distribusi eksponensial, dimana FKP yang diberikan oleh persamaan (2) dapat ditulis dalam bentuk $f(y)=\exp \left[-y^{\gamma} \lambda^{-\gamma}+(\gamma-1) \ln \left(\frac{y}{\lambda}\right)+\ln \left(\frac{\gamma}{\lambda}\right)\right]$,

dengan $a(y)=y^{\gamma}, b(\lambda)=-\lambda^{-\gamma}, c(\lambda)=\ln (\gamma / \lambda)$, $d(y, \lambda)=\ln (y / \lambda) \quad$ dan $\quad E\left(Y^{\gamma}\right)=\lambda^{\gamma}, \quad$ serta $\operatorname{var}\left(Y^{\gamma}\right)=\lambda^{2 \gamma}$. Berdasarkan model linier tergeralisir atau generalized linear model (GLM), fungsi penghubung (link function) untuk FKP pada persamaan (7) adalah invers dari $\mu$, yaitu

$$
\lambda=g(\mu)=\mu^{1 / \gamma},
$$

dengan parameter natural adalah $\lambda$. Fungsi penghubung yang diberikan oleh persamaan (8) adalah bukan fungsi penghubung kanonik (canonical link function), dimana $b(\lambda)=-\lambda^{\gamma}$ adalah bukan fungsi identitas.

Sebagai pengembangan distribusi Weibull, parameter natural, yakni parameter skala $(\lambda)$ dapat dinyatakan dalam fungsi dari kovariat atau fungsi dari parameter regresi (Lawless, 2003; Rinne, 2009). Diketahui parameter skala adalah bilangan riil positip, sehinga dapat dinyatakan dalam hubungan

$\ln \lambda=\boldsymbol{\beta}^{T} \mathbf{x}=\beta_{0}+\beta_{1} X_{1}+\cdots+\beta_{p} X_{p}$,

dengan

$\boldsymbol{\beta}^{T}=\left[\beta_{0} \beta_{1} \cdots \beta_{p}\right]$ adalah vektor parameter regresi berdimensi $p+1$ dan $\mathbf{x}=\left[\begin{array}{llll}X_{0} & X_{1} & \cdots & X_{p}\end{array}\right]^{T}$ adalah vektor kovariat atau peubah bebas dengan $X_{0}=1$ (Hanagal, 2004, 2005; Suyitno dkk, 2016; 2017) Model-model regresi Weibull dapat diperoleh dari persamaan (5), (3) dan (2) dengan parameter skala dinyatakan dalam parameter regresi yang didefinisikan oleh persamaan (9), dan berturut-turut diperoleh model regresi untuk mean peubah acak $Y$ adalah

$$
\mu_{Y}(\boldsymbol{\theta}, \mathbf{x})=\Gamma\left(\frac{1}{\gamma}+1\right) \exp \left[\boldsymbol{\beta}^{T} \mathbf{x}\right],
$$

model fungsi survival adalah

$$
S(y, \boldsymbol{\theta})=\exp \left[-y^{\gamma} \exp \left[-\gamma y^{\gamma} \boldsymbol{\beta}^{T} \mathbf{x}\right]\right.
$$

dan FKP yang memuat kovariat diberikan oleh

$$
\begin{aligned}
f(y, \boldsymbol{\theta})= & \gamma y^{\gamma-1} \exp \left[-\gamma \exp \left[\boldsymbol{\beta}^{T} \mathbf{x}\right]\right] \times \\
& \exp \left[-y^{\gamma} \exp \left[-\gamma \boldsymbol{\beta}^{T} \mathbf{x}\right]\right],
\end{aligned}
$$

dengan $\quad \boldsymbol{\theta}=\left[\begin{array}{lllll}\gamma & \beta_{0} & \beta_{1} \cdots & \beta_{p}\end{array}\right]^{T} \quad$ adalah vektor berdimensi $p+2$.

\section{Penaksiran Parameter Model RWU}

Penaksiran parameter model RWU terdiri dari penaksiran parameter-parameter model $\mu_{Y}(\boldsymbol{\theta}, \mathbf{x})$ yang diberikan oleh persamaan (10) dan model fungsi survival $S(y, \boldsymbol{\theta})$ yang diberikan oleh persamaan (11) dengan metode MLE. Tahap awal metode MLE adalah mendefinisikan fungsi 
likelihood. Misalkan diberikan $n$ sampel acak $\left(Y_{i}, \mathbf{x}_{i}\right), i=1,2, \cdots, n$ dengan $Y_{i}$ adalah sampel acak respon yang idependen dan berdistribusi identik, yakni $\quad Y_{i} \sim W\left(\gamma, \exp \left(\boldsymbol{\beta}^{T} \mathbf{x}_{i}\right) \quad\right.$ dan $\mathbf{x}_{i}^{T}=\left[\begin{array}{lllll}X_{0} & X_{1 i} & X_{2 i} & \cdots & X_{p i}\end{array}\right]$ adalah sampel acak kovariat untuk $i=1,2, \cdots, n$. Berdasarkan FKP yang diberikan oleh persamaan (12) fungsi likelihood didefinisikan oleh

$$
\begin{aligned}
\ell(\boldsymbol{\theta})= & \prod_{i=1}^{n} f\left(\boldsymbol{\theta} \mid y_{i}, \mathbf{x}_{i}\right) \\
= & \prod_{i=1}^{n}\left(\gamma y_{i}^{\gamma-1} \exp \left[-\gamma \exp \left[\boldsymbol{\beta}^{T} \mathbf{x}_{i}\right]\right]\right) \times \\
& \prod_{i=1}^{n}\left(\exp \left[-y_{i}^{\gamma} \exp \left[-\gamma \boldsymbol{\beta}^{T} \mathbf{x}_{i}\right]\right]\right)
\end{aligned}
$$

Penaksir maximum likelihood (ML) model regresi Weibull adalah nilai vektor $\hat{\boldsymbol{\theta}}$ yang memaksimumkan fungsi likelihood $\ell(\boldsymbol{\theta})$ yang diberikan oleh persamaan (13) dan juga memaksimumkan fungsi logaritma natural (loglikelihood) dari fungsi likelihood $\ell(\boldsymbol{\theta})$. Fungsi logaritma natural dari fungsi likelihood (13) diberikan oleh

$$
\begin{aligned}
L(\boldsymbol{\theta})= & \ln (\ell(\boldsymbol{\theta})) \\
= & \sum_{i=1}^{n}\left(\ln \gamma+(\gamma-1) \ln y_{i}-\gamma \boldsymbol{\beta}^{T} \mathbf{x}_{i}\right)- \\
& \sum_{i=1}^{n}\left(y_{i}^{\gamma} \exp \left[-\gamma \boldsymbol{\beta}^{T} \mathbf{x}_{i}\right]\right) .
\end{aligned}
$$

Penaksir ML $(\hat{\boldsymbol{\theta}})$ diperoleh dengan menyelesaikan persamaan likelihood yang diberikan oleh

$\frac{\partial L(\boldsymbol{\theta})}{\partial \boldsymbol{\theta}}=\mathbf{0}$,

dengan $\mathbf{0}$ adalah vektor nol berdimensi $p+2$ dan ruas kanan persamaan (15) adalah vektor gradien berdimensi $p+2$, yaitu

$$
\begin{aligned}
\mathbf{g}(\boldsymbol{\theta}) & =\frac{\partial L(\boldsymbol{\theta})}{\partial \boldsymbol{\theta}} \\
& =\left[\frac{\partial L(\boldsymbol{\theta})}{\partial \gamma} \frac{\partial L(\boldsymbol{\theta})}{\partial \beta_{0}} \frac{\partial L(\boldsymbol{\theta})}{\partial \beta_{1}} \cdots \frac{\partial L(\boldsymbol{\theta})}{\partial \beta_{p}}\right]^{T} .
\end{aligned}
$$

Komponen-komponen vektor gradien (16) dapat dinyatakan dalam bentuk umum, yaitu masingmasing adalah

$$
\begin{aligned}
\frac{\partial L(\boldsymbol{\theta})}{\partial \gamma}= & \sum_{i=1}^{n}\left(\frac{1}{\gamma}+\ln y_{i}-\boldsymbol{\beta}^{T} \mathbf{x}_{i}\right)- \\
& \sum_{i=1}^{n}\left(y_{i}^{\gamma} \ln y_{i} \exp \left[-\gamma \boldsymbol{\beta}^{T} \mathbf{x}_{i}\right]\right)+ \\
& \sum_{i=1}^{n}\left(y_{i}^{\gamma} \boldsymbol{\beta}^{T} \mathbf{x}_{i}\left(\ln y_{i}\right) \exp \left[-\gamma \boldsymbol{\beta}^{T} \mathbf{x}_{i}\right]\right),
\end{aligned}
$$

dengan $\boldsymbol{\beta}^{T} \mathbf{x}_{i}=\beta_{0}+\beta_{1} X_{1 i}+\cdots+\beta_{p} X_{p i}$ dan

$$
\begin{aligned}
& \frac{\partial L(\boldsymbol{\theta})}{\partial \beta_{k}}= \\
& \sum_{i=1}^{n}\left(-\beta_{k} X_{k i}+\gamma y_{i}^{\gamma} X_{k i} \exp \left[-\gamma-\boldsymbol{\beta}^{T} \mathbf{x}_{i}\right]\right),
\end{aligned}
$$

untuk $k=0,1, \cdots, p$. Diketahui bahwa komponenkomponen vektor gradien yang diberikan oleh persamaan (17) dan (18) terdiri persamaanpersamaan nonlinier yang saling bergantungan, sehingga solusi eksak persamaan (15) untuk mendapatkan penaksir eksak ML tidak dapat ditemukan secara analitis. Metode alternatif dalam menyelesaikan persamaan (15) untuk mendapatkan penaksir ML $(\hat{\boldsymbol{\theta}})$ adalah metode iteratif Newton Raphson.

Penentuan penaksir ML $(\hat{\boldsymbol{\theta}})$ dengan metode Newton-Raphson diperlukan penghitungan vektor gradien dan matriks Hessian. Vektor gradien $\mathbf{g}(\boldsymbol{\theta})$ diberikan oleh persamaan (16) dan matriks Hessian $\mathbf{H}(\boldsymbol{\theta})$ adalah matriks simetri orde $p+2$, yaitu matriks turunan orde kedua dari fungsi $l o g$ likelihhod (14). Bentuk umum matriks Hessian adalah

$$
\mathbf{H}(\boldsymbol{\theta})=\left[\begin{array}{ll}
\frac{\partial^{2} L(\boldsymbol{\theta})}{\partial \gamma^{2}} & \frac{\partial^{2} L(\boldsymbol{\theta})}{\partial \gamma \partial \boldsymbol{\beta}^{T}} \\
\frac{\partial^{2} L(\boldsymbol{\theta})}{\partial \boldsymbol{\beta} \partial \gamma} & \frac{\partial^{2} L(\boldsymbol{\theta})}{\partial \boldsymbol{\beta} \partial \boldsymbol{\beta}^{T}}
\end{array}\right]_{(p+2) \times(p+2)},
$$

dengan

$$
\frac{\partial^{2} L(\boldsymbol{\theta})}{\partial \boldsymbol{\beta} \partial \boldsymbol{\beta}^{T}}=\left[\begin{array}{cccc}
\frac{\partial^{2} L(\boldsymbol{\theta})}{\partial \beta_{0}^{2}} & \frac{\partial^{2} L(\boldsymbol{\theta})}{\partial \beta_{0} \partial \beta_{1}} & \cdots & \frac{\partial^{2} L(\boldsymbol{\theta})}{\partial \beta_{0} \partial \beta_{p}} \\
\frac{\partial^{2} L(\boldsymbol{\theta})}{\partial \beta_{1} \partial \beta_{0}} & \frac{\partial^{2} L(\boldsymbol{\theta})}{\partial \beta_{1}^{2}} & \cdots & \frac{\partial^{2} L(\boldsymbol{\theta})}{\partial \beta_{1} \partial \beta_{p}} \\
\vdots & \vdots & \ddots & \vdots \\
\frac{\partial^{2} L(\boldsymbol{\theta})}{\partial \beta_{p} \partial \beta_{0}} & \frac{\partial^{2} L(\boldsymbol{\theta})}{\partial \beta_{p} \partial \beta_{1}} & \cdots & \frac{\partial^{2} L(\boldsymbol{\theta})}{\partial \beta_{p}^{2}}
\end{array}\right] .
$$

Berdasarkan turunan orde pertama yang diberikan oleh persamaan (17) dan (18), elemen-elemen matriks Hessian $\mathbf{H}(\boldsymbol{\theta})$ yang diberikan oleh persamaan (19) dapat dinyatakan dalam bentuk umum. Elemen-elemen diagonal utama adalah

$$
\begin{aligned}
\frac{\partial^{2} L(\boldsymbol{\theta})}{\partial \gamma^{2}}= & \sum_{i=1}^{n}\left(\frac{1}{\gamma^{2}}-y_{i}^{\gamma}\left(\ln y_{i}\right)^{2} \exp \left[-\gamma \boldsymbol{\beta}^{T} \mathbf{x}_{i}\right]\right)+ \\
& 2 \sum_{i=1}^{n}\left(y_{i}^{\gamma}\left(\ln y_{i}\right)\left(\boldsymbol{\beta}^{T} \mathbf{x}_{i}\right) \exp \left[-\gamma \boldsymbol{\beta}^{T} \mathbf{x}_{i}\right]\right)- \\
& \sum_{i=1}^{n}\left(y_{i}^{\gamma}\left(\boldsymbol{\beta}^{T} \mathbf{x}_{i}\right)^{2} \exp \left[-\gamma \boldsymbol{\beta}^{T} \mathbf{x}_{i}\right]\right) \\
\frac{\partial^{2} L(\boldsymbol{\theta})}{\partial \beta_{k}^{2}}= & \sum_{i=1}^{n}\left(-\gamma^{2} y_{i}^{\gamma}\left(X_{k i}\right)^{2} \exp \left[-\gamma \boldsymbol{\beta}^{T} \mathbf{x}_{i}\right]\right)
\end{aligned}
$$


untuk $k=0,1, \cdots, p$. Elemen-elemen nondiagonal dapat dinyatakan dalam bentuk umum, yaitu untuk $k \neq t ; k=0,1, \cdots, p$ dan $t=0,1, \cdots, p$ didapat

$$
\begin{aligned}
\frac{\partial^{2} L(\boldsymbol{\theta})}{\partial \gamma \partial \beta_{k}}= & \frac{\partial^{2} L(\boldsymbol{\theta})}{\partial \beta \partial \gamma} \\
= & \sum_{i=1}^{n}\left(-X_{k i}+\gamma y_{i}^{\gamma} \ln y_{i} X_{k i} \exp \left[-\gamma \boldsymbol{\beta}^{T} \mathbf{x}_{i}\right]\right)+ \\
& \sum_{i=1}^{n}\left(y_{i}^{\gamma} X_{k i} \exp \left[-\gamma \boldsymbol{\beta}^{T} \mathbf{x}_{i}\right]\right)+ \\
& \sum_{i=1}^{n}\left(-\gamma y_{i}^{\gamma} X_{k i}\left(\boldsymbol{\beta}^{T} \mathbf{x}_{i}\right) \exp \left[-\gamma \boldsymbol{\beta}^{T} \mathbf{x}_{i}\right]\right),
\end{aligned}
$$

dan

$$
\begin{aligned}
\frac{\partial^{2} L(\boldsymbol{\theta})}{\partial \beta_{t} \partial \beta_{k}} & =\frac{\partial^{2} L(\boldsymbol{\theta})}{\partial \beta_{k} \partial \beta_{t}} \\
& =\sum_{i=1}^{n}\left(-\gamma^{2} y_{i}^{\gamma} X_{k i} X_{t i} \exp \left[-\gamma \boldsymbol{\beta}^{T} \mathbf{x}_{i}\right]\right) .
\end{aligned}
$$

Berdasarkan hasil penghitungan komponenkomponen vektor gradien $\mathbf{g}(\boldsymbol{\theta})$ yang diberikan oleh persamaan (17) dan (18), serta elemen-elemen matriks Hessian $\mathbf{H}(\boldsymbol{\theta})$ yang diberikan oleh persamaan (20) sampai dengan (23), sekarang penaksir parameter model RWU $(\hat{\boldsymbol{\theta}})$ dapat ditemukan melalui algoritma iterasi NewtonRaphson yang diberikan oleh

$$
\hat{\boldsymbol{\theta}}^{(q+1)}=\hat{\boldsymbol{\theta}}^{(q)}-\left[\mathbf{H}\left(\hat{\boldsymbol{\theta}}^{(q)}\right)\right]^{-1} \mathbf{g}\left(\hat{\boldsymbol{\theta}}^{(q)}\right), q=0,1, \cdots
$$

(Khuri, 2003).

\section{Pengujian Hipotesis Parameter Regresi}

Pengujian hipotesis parameter regresi model RWU terdiri dari pengujian secara serentak dan parsial. Pengujian parameter regresi secara serentak bertujuan untuk mengkonfirmasi apakah parameter-parameter yang telah ditaksir memberikan model regresi yang cocok (fit) atau belum. Hipotesis pengujian parameter regresi secara serentak adalah

$$
\begin{aligned}
& \mathrm{H}_{0}: \beta_{1}=\beta_{2}=\cdots=\beta_{p}=0 \\
& \mathrm{H}_{1}: \text { Paling sedikit ada satu } \beta_{k} \neq 0, \\
& \quad \text { untuk } k=1,2, \cdots, p .
\end{aligned}
$$

Himpunan parameter di bawah populasi adalah

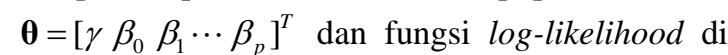
bawah populasi diberikan oleh persamaan (14). Nilai maksimum fungsi log-likelihood (14) adalah $L(\hat{\boldsymbol{\theta}})$ dengan $\hat{\boldsymbol{\theta}}=\left[\hat{\gamma} \hat{\beta}_{0} \hat{\beta}_{1} \cdots \hat{\beta}_{p}\right]^{T}$ yang diperoleh melalui iterasi Newton-Raphson (24). Himpunan parameter di bawah hipotesis nol adalah $\boldsymbol{\theta}_{0}=\left[\begin{array}{ll}\gamma_{0} & \beta_{00}\end{array}\right]^{T}$ dan fungsi log-likelihood di bawah $\mathrm{H}_{0}$ adalah

$$
\begin{aligned}
L\left(\boldsymbol{\theta}_{0}\right) & =\ln \left(\ell\left(\boldsymbol{\theta}_{0}\right)\right) \\
& =\ldots
\end{aligned}
$$

$$
\begin{aligned}
L\left(\boldsymbol{\theta}_{0}\right)= & \ln \left(\ell\left(\boldsymbol{\theta}_{0}\right)\right) \\
= & \sum_{i=1}^{n}\left(\ln \gamma_{0}+\left(\gamma_{0}-1\right) \ln y_{i}-\gamma_{0} \beta_{00}\right)- \\
& \sum_{i=1}^{n}\left(y_{i}^{\gamma} \exp \left[-\gamma_{0} \beta_{00}\right]\right) .
\end{aligned}
$$

Nilai maksimum fungsi log-likelihood di bawah hipotesis nol $\left(\mathrm{H}_{0}\right)$ adalah

$L\left(\hat{\boldsymbol{\theta}}_{0}\right)$ dengan $\hat{\boldsymbol{\theta}}_{0}=\left[\hat{\gamma}_{0} \hat{\beta}_{00}\right]^{T}$ dapat diperoleh mengunakan metode itererasi Newton-Raphson.

Statistik uji pengujian hipotesis nol yang dinyatakan dalam persamaan (25) adalah statistik Wilk's likelihood ratio yang diberikan oleh

$W=2\left(L(\hat{\boldsymbol{\theta}})-L\left(\hat{\boldsymbol{\theta}}_{0}\right)\right.$,

dengan $W \sim \chi_{p}^{2}$. Daerah kritis pengujian hipotesis ini adalah menolak $\mathrm{H}_{0}$ pada taraf uji $\alpha$ jika $W>\chi_{(1-\alpha ; p)}^{2}($ Pawitan, 2001).

Pengujian hipotesis parameter regresi secara parsial untuk mengetahui apakah kovariat tertentu secara idividual berpengaruh terhadap model regresi. Hipotesis pengujian secara parsial adalah $\mathrm{H}_{0}: \beta_{k}=0$ $\mathrm{H}_{1}: \beta_{k} \neq 0$, untuk suatu $k \in\{1,2, \cdots, p\}$.

Statistik uji pengujian hipotesis nol yang diberikan oleh persamaan (27) adalah statistik Wald yang diberikan oleh

$W_{0}=\frac{\hat{\beta}_{k}-E\left(\hat{\beta}_{k}\right)}{\sqrt{\operatorname{var}\left(\hat{\beta}_{k}\right)}}$.

Di bawah hipotesis nol $E\left(\hat{\beta}_{k}\right)=\beta_{k}=0$ sehingga didapat

$W_{0}=\frac{\hat{\beta}_{k}}{\sqrt{\operatorname{var}\left(\hat{\beta}_{k}\right)}} \sim N(0,1)$,

dengan $\operatorname{var}\left(\hat{\beta}_{k}\right)$ adalah elemen diagonal utama ke$k+2$ matriks informasi Fisher $[\mathbf{I}(\hat{\boldsymbol{\theta}})]=-[\mathbf{H}(\hat{\boldsymbol{\theta}})]^{-1}$. Daerah kritis pengujian hipotesis (27) adalah menolak $\mathrm{H}_{0}$ pada taraf uji $\alpha$, jika $\left|W_{0}\right|>Z_{1-\alpha / 2}$.

Statistik uji alternatif pengujian hipotesis (27) adalah kuadrat dari statistik Wald yang diberikan oleh persamaan (28), yaitu

$W_{0}^{2}=\frac{\hat{\beta}_{k}^{2}}{\operatorname{var}\left(\hat{\beta}_{k}\right)}$,

dengan $W_{0}^{2} \sim \chi_{1}^{2}$. Hipotesis nol (27) ditolak pada taraf uji $\alpha$ jika $W_{0}^{2}>\chi_{(1-\alpha ; 1)}^{2}($ Pawitan, 2001).

\section{Tahapan Analisis Data}

Garis besar tahapan analisis data pada model RWU adalah sebagai berikut :

1. Pengumpulan data sampel

2. Penaksiran parameter FKP original versi skalabentuk yang diberikan oleh persamaan (2). 
Penaksiran parameter dapat menggunakan metode MLE.

3. Pengujian distribusi data respon, yakni pengujian apakah data sampel respon berdistribusi Weibull versi skala-bentuk. Pengujian distribusi dapat menggunakan uji Kolmogorov-Smirnov.

4. Pendeteksian multikolinieritas antar peubah bebas atau kovariat. Pendeteksian multikolinieritas antar kovariat dapat menggunakan nilai variance inflating factor (VIF).

5. Penaksiran parameter model RWU

6. Pengujian hipotesis parameter regresi

7. Penghitungan ukuran kebaikan. Beberapa ukuran kebaikan model RWU antara lain :

(a). Akaike information Criterion (AIC) yang diberikan oleh

$A I C=-2 L(\hat{\boldsymbol{\theta}})+v$,

dengan $v$ adalah banyaknya parameter dalam model (Pawitan, 2001).

(b). Bayesian information criterion (BIC) yang diberikan oleh

$B I C=-2 L(\hat{\boldsymbol{\theta}})+v \ln n$, dengan $n$ menyatakan ukuran sampel.

(c). Mean squares Error (MSE) yang diberikan oleh

$M S E=\frac{1}{(n-v)} \sum_{i=1}^{n}\left(y_{i}-\oiint_{Y_{i}}\right)^{2}$ (Fotheringham , dkk, 2002).

\section{Kesimpulan}

Kesimpulan penelitian ini adalah

1. Model regresi Weibull adalah model dari mean respon dan atau model fungsi survival dan atau model fungsi kepadatan peluang distribusi Weibull univariat dengan parameter skala dinyatakan dalam fungsi dari parameter regresi.

2. Penaksir eksak maximum likelihood parameter model regresi Weibull univariat tidak dapat ditemukan secara analitikal, dan hampiran penaksir maximum likelihood diperoleh dengan metode iterativ Newton-Raphson.

3. Pengujian hipotesis parameter regresi model regresi Weibull univariat terdiri dari pengujian parameter regresi secara serentak dan parsial. Statistik uji pengujian secara serentak adalah statistik Wilk's likelihood ratio yang diturunkan dengan metode likelihood ratio test (LRT). Statistik Wilk berdistribusi Chikuadrat. Statistik uji pengujian parameter regresi secara parsial adalah statistik Wald.
Statistik Wald diturunkan berdasarkan sifat asimtotik penaksir maximum likelihood. Statistik Wald berdistribusi normal baku, dan kuadrat dari statistik Wald berdistribusi Chikuadrat dengan derajat bebas satu.

\section{Daftar Pustaka}

Fotheringham, A.S., Brundson, C. dan Charlton, M. (2002). Geographically Weighted Regression: the analysis of spatially varying relationships. John Wiley \& Sons Ltd, England.

Hanagal, D.D. (2004). Parametric Bivariate Regression Analysis Based on Censored Samples: A Weibull Model. Economic Quality Control, Vol 19, No. 1, 1 -; CHeldermann Verlag ISSN 0940-5151.

Hanagal, D.D. (2005). A Bivariate Weibull Regression Model. Economic Quality Control,Vol 20, No. 1, 1 -; CHeldermann Verlag ISSN 0940-5151.

Hanagal, D.D. (2005). Weibull Extension of a Bivariate Exponential Regression Model Economic Quality Control, Vol 20, No. 2, 149 -; CHelderman Verlag ISSN 09405151.

Khuri, A.I. (2003). Advanced Calculus with Applications in Statistics. $2^{\text {nd }}$ Edition. John Wiley \& Sons, Inc., Hoboken, New Jersey.

Lawless, J. F. (2003). Statistical Models and Methods for lifetime Data. 2nd edition, John Wiley \& Sons. Inc., Hoboken, New Jersey.

O’Quigley, J. dan Roberts, A. (1980). Weibull: $A$ Regression Model For Survival Time Studies. Computer Program in Biomedicine 12 (1980) 14-18.

Pawitan, Y. (2001). In All Likelihood. Statistical Modelling and Inference Using Likelihood. Clarendon Press-Oxford.

Rinne, H. (2009). The Weibull Distribution A Handbook. CRC Press Taylor and Francis Group.

Suyitno, Purhadi, Sutikno dan Irhamah. (2016). Penaksiran Parameter Model Regresi Bivariat. Prosiding Seminar Nasional Matematika \& Pendidikan Matematikan (Sendika) Vol. 2, No. 1, (2016), pp 266271, ISSN : 2459-962X.

Suyitno, Purhadi, Sutikno dan Irhamah. (2017). Multivariate Weibull Regression Model. Far East Journal of Mathematical Sciences, Vol. 101, No. 9, (2017), pp 1977-1992. 
